NBER WORKING PAPER SERIES

\title{
ABORTION LEGALIZATION AND CHILD LIVING CIRCUMSTANCES: WHO IS THE "MARGINAL CHILD?"
}

\author{
Jonathan Gruber \\ Phillip Levine \\ Douglas Staiger
}

Working Paper 6034

\author{
NATIONAL BUREAU OF ECONOMIC RESEARCH \\ 1050 Massachusetts Avenue \\ Cambridge, MA 02138 \\ May 1997
}

We are grateful to Amber Batata for superb research assistance, and to Larry Katz and seminar participants at Harvard for useful comments. Gruber acknowledges funding from the National Institute on Aging administered by the National Bureau of Economic Research. This paper is part of NBER's research programs in Children, Health Care and Public Economics. Any opinions expressed are those of the authors and not those of the National Bureau of Economic Research.

(C) 1997 by Jonathan Gruber, Phillip Levine and Douglas Staiger. All rights reserved. Short sections of text, not to exceed two paragraphs, may be quoted without explicit permission provided that full credit, including $\mathbb{C}$ notice, is given to the source. 
Abortion Legalization and Child Living

Circumstances: Who is the "Marginal Child?"

Jonathan Gruber, Phillip Levine and Douglas Staiger

NBER Working Paper No. 6034

May 1997

JEL Nos. I18, J13

Children, Health Care and Public Economics

\begin{abstract}
We estimate the impact of changes in abortion access in the early 1970s on the average living standards of cohorts born in those years. In particular, we address the selection inherent in the abortion decision: is the marginal child who is not born when abortion access increases more or less disadvantaged than the average child? Legalization of abortion in five states around 1970, followed by legalization nationwide due to the 1973 Roe v. Wade decision, generates natural variation which can be used to estimate the effect of abortion access. We find that cohorts born after abortion was legalized experienced a significant reduction in a number of adverse outcomes. Our estimates imply that the marginal child who was not born due to legalization would have been $70 \%$ more likely to live in a single parent family, $40 \%$ more likely to live in poverty, $50 \%$ more likely to receive welfare, and $35 \%$ more likely to die as an infant. These selection effects imply that the legalization of abortion saved the government over \$14 billion in welfare expenditures through 1994.
\end{abstract}

Jonathan Gruber

Department of Economics

Massachusetts Institute of Technology

E52-355

50 Memorial Drive

Cambridge, MA 02142-1347

and NBER

gruberj@mit.edu

Douglas Staiger

Kennedy School of Government

Harvard University

79 JFK Street

Cambridge, MA 02138

and NBER

dougs@ksgrsch.harvard.edu
Phillip Levine

Department of Economics

Wellesley College

Wellesley, MA 02181

and NBER

plevine@wellesley.edu 
Access to abortion is one of the most contentious public policy issues facing the United States today. The period since the legalization of abortion under the Roe v. Wade decision of 1973 has been marked by incessant debate over the appropriate government financing and legal status of abortions. Meanwhile, pregnancy resolution through abortion is a very common outcome in the U.S.; roughly $25 \%$ of all pregnancies are aborted (Ventura et al., 1995). As a result, major changes in abortion access could have substantial effects on the birth rate. Indeed, Levine et al. (1996) find that the legalization of abortion in the early 1970 s led to a $5 \%-10 \%$ reduction in the birthrate. ${ }^{1}$

To the extent that abortion access reduces the size of a birth cohort, one question of particular interest from a policy perspective is the effect on the living circumstances of the children that are born. Inherently, this is a question about the marginal child: Would those children who were not born because of abortion access have lived in better or worse circumstances than the average child in their cohort? For example, if the women who terminate their births would have borne children into families that were single female-headed and/or poor, then improved abortion access could lead to a reduction in the rate of child poverty and welfare utilization. ${ }^{2}$ Yet there is little direct evidence on the effect of abortion access on child living circumstances.

The key to answering this question is understanding how abortion influences the selection of which women carry pregnancies to term. A priori, the direction and size of selection is unclear. On the one hand, if women use abortion to avoid bearing children into adverse circumstances, there may be positive selection: the living circumstances of the marginal child are worse than the average

\footnotetext{
${ }^{1}$ Although Kane and Staiger (1996) and Levine, Trainor, and Zimmerman (1996) do not find increases in the birthrate from more modest changes in abortion access.

${ }^{2}$ This point has been recognized, in reverse, in the recent debates over welfare reform, as opponents of abortion expressed concern that reducing welfare generosity could lead many single (potential) mothers to terminate their pregnancies.
} 
child, so that increased abortion access will raise average living standards of the children who are born. This follows from the standard model of the child quality/quantity tradeoff (Becker, 1981). As applied by, for example, Grossman and Joyce (1990), this model implies that as abortion access increases women will terminate pregnancies that would result in lower quality children. In their application, the direct implication is increased termination of unhealthy fetuses. But a natural extension is to the termination of pregnancies that would result in children living in worse circumstances.

On the other hand, if the most disadvantaged women are constrained in their abortion access, either geographically or financially, then there may be negative selection. In fact, there appears to be a strong geographic correlation between access and income: In 1980, 27.2\% of counties with poverty rates of $15 \%$ or below had abortion providers, while only $10.6 \%$ of counties with poverty rates above $15 \%$ had providers. ${ }^{3}$ As a result, the poorest women, who bear children on average into the worst circumstances, may be less likely to abort. Moreover, abortion access may itself change the mix of pregnancies. For example, Akerlof, Yellen and Katz (1996) suggest that increased access to abortion could increase the share of births out of wedlock by reducing the incidence of "shotgun" marriages; abortion access would be correlated with a reduction in average living circumstances (negative selection) through this mechanism. Ultimately, the direction of selection, and the effects on subsequent child living circumstances, is an empirical question.

There are three types of studies which have addressed this selection question to some extent. The first is state-level analyses of abortion, which regress abortion rates on state characteristics. Such analyses consistently find a strong positive correlation between abortion rates and state income

\footnotetext{
${ }^{3}$ Author's tabulation of 1980 census data, using data on abortion provider location from Kane and Staiger (1996).
} 
per capita (ie. Blank et al., 1994). Even as states get richer and increase abortion access, however, there is no obvious implication for which women within the states are obtaining abortions, so that these studies offer little insight into the process of selection.

The second type of study is micro-data analyses of the abortion decision, focusing on the characteristics of women that are correlated with their decision to terminate their pregnancies. These studies yield mixed results: abortion among teens is more likely if they are unmarried (Joyce, 1988), but among unmarried teens it is positively correlated with their mother's education and with living with both parents (Cooksley, 1990; Lundberg and Plotnick, 1995). But these studies do not necessarily have implications for average living standards, since there may be selection along unobservable dimensions which counteracts, or augments, the selection that is observed. Moreover, most of these studies suffer from the notoriously poor quality of data on abortion that is available in micro-data surveys, and in particular in the National Longitudinal Survey of Youth (NLSY), the data used by Cooksley and Lundberg and Plotnick. Jones and Forrest (1992) find that only $40 \%$ of abortions are reported in the NLSY, and that underreporting of abortions is largest for disadvantaged groups such as non-whites and unmarried women. ${ }^{4}$ If the quality of the abortion data varies systematically with living circumstances, this will bias estimates of selection using micro data.

Finally, and most closely related to our approach, is studies of the effect of abortion availability on infant outcomes. A large number of studies demonstrate that there is positive selection on fetal health: abortion access, as measured by number of providers or abortion rates, is correlated with a sizeable improvement in infant outcomes such as low birthweight or neonatal mortality (Grossman and Jacobowitz, 1981; Corman and Grossman, 1985; Joyce, 1987; Grossman

\footnotetext{
${ }^{4}$ This figure is computed by comparing reported abortions in this nationally representative sample of youth to administrative data on abortions in the U.S. in the comparable age range.
} 
and Joyce, 1990). ${ }^{5}$ But this evidence may not be pertinent for assessing the relative living circumstances of cohorts that do and do not have access to abortion; the pregnancies that are terminated may have been those of well-off women who had unhealthy fetuses, so that selection on living circumstances is negative even as selection on fetal health is positive. Moreover, the effects of marginal variation in provider access may be different than the large changes inherent in legalization. ${ }^{6}$

In this paper, we take a new and more direct approach to measuring the effect of abortion access on the living circumstances of subsequent cohorts of children. We examine the effect of the largest change in abortion availability in the U.S., increased access in the early 1970s through Roe v. Wade and comparable state laws, on the living circumstances of the cohorts of children born in these years. More specifically, following Levine et al. (1996), we note that Roe v. Wade followed on the heels of abortion legalization in five states around 1970. This generates two "natural experiments" for analyzing the effect of abortion access: the change in these five states, versus the remainder of the country, around 1970 , and the change for the remainder of the country, versus these five states, around the time of Roe v. Wade (1973). The large reduction in the number of births associated with legalization, as documented by Levine et al., provides the impetus for focusing on the resultant living standards of the remaining cohort of children.

\footnotetext{
${ }^{5}$ Currie, Nixon, and Cole (1996) also find that abortion availability, as measured by number of abortion providers, is correlated with improved birth outcomes; but they do not find any effect of abortion funding restrictions.

${ }^{6}$ This follows from the fact, noted above, that Levine et al. (1996) find much larger effects of legalization on birth rates than do other studies of variation in Medicaid funding restrictions (Levine, Trainor, and Zimmerman, 1996) or provider access (Kane and Staiger, 1996). Grossman and Jacobowitz (1981) do include a variable for abortion reform in 1970 in their cross-sectional neo-natal mortality regression; but it is unclear whether this includes the appropriately defined set of repeal states (see the discussion below), and this approach does not exploit the changes in legalization over time.
} 
We carry out our analysis using the 5\% Public Use Micro Sample (PUMS) of the 1980 Census. The PUMS data allow us to observe the living circumstances in 1980 for cohorts of children by state of birth and year of birth. In addition, the PUMS provides sufficiently large samples to identify the relatively small expected effects on average living standards. We also use data on birth rates and birth outcomes available by state and year of birth from the U.S. Vital Statistics.

We find evidence of sizeable positive selection: the average living circumstances of cohorts of children born immediately after abortion became legalized improved substantially relative to preceding cohorts, and relative to places where the legal status of abortion was not changing. Our results suggest that the marginal children who were not born as a result of abortion legalization would have systematically been born into worse circumstances had the pregnancies not been terminated: they would have been $70 \%$ more likely to live in a single parent household, $40 \%$ more likely to live in poverty, $35 \%$ more likely to die during the first year of life, and $50 \%$ more likely to be in a household collecting welfare. The last of these finding implies that the selection effects operating through the legalization of abortion saved the government over $\$ 14$ billion in welfare payments through the year 1994.

We begin, in Part I, with a description of the policy change that underlies our study, and the resulting empirical framework that it motivates. In Part II, we describe our data and empirical strategy. Part III presents our results, and Part IV concludes. 


\section{Part I: Background and Empirical Strategy}

The effect of abortion access on the average living circumstances of birth cohorts is identified by the major changes in the legal status of abortion across the U.S. states in the early 1970s. For several decades prior to the late 1960s, abortion was illegal in every state in America. Between 1967 and 1970, a number of states implemented modest reforms making it legal for some women to obtain abortions under very special circumstances, such as rape or incest. Abortion then became widely available in five states in 1970. In four of these states, there was a repeal of anti-abortion laws: New York, Washington, Alaska, and Hawaii. In the fifth, California, there was a "de facto" legalization, since in late 1969 the California State Supreme Court ruled that the pre-1967 law outlawing abortion was unconstitutional. ${ }^{7}$ Following the 1973 Supreme Court decision in Roe vs. Wade, abortion became legal in all states.

This legislative history enables us to employ a "differences-in-differences" strategy to estimate the effect of abortion legalization on average living circumstances, following Levine et al. (1996). The basic idea is to compare differences over time in the living circumstances of cohorts born in the "repeal" states (the five states listed above), relative to cohorts born in other states. ${ }^{8}$ We depict this strategy hypothetically in Figure 1, for a typical measure of living circumstances, the percentage of the cohort living in poverty. We consider the case of positive selection, whereby abortion legalization improves living standards. The line in this figure is the difference in poverty

\footnotetext{
${ }^{7}$ Furthermore, evidence indicates that legal abortion was widely available in California beginning in 1970, with legal abortion rates among women living in California being comparable to rates for women living in New York. See Potts et al. (1977) pp. 75-77, 149, and see Garrow (1994) pp. 377$80,410-11$, and 457 , and references cited in footnotes 25 and 76 from chapter 7.

${ }^{8}$ Levine et al. (1996) show that there was little effect of the modest reforms in other states in the late $1960 \mathrm{~s}$, so we include these states in our control group. Our results are very similar if we exclude this group of states from our controls.
} 
rates between the cohorts born in repeal and non-repeal states over time. Time in this figure refers to the year of birth of the cohort.

In region $\mathrm{A}$, which is the pre-1970 cohorts, there is some constant difference in poverty rates between these two sets of states (k), due to underlying differences in the population of residents. Then, under our assumption of positive selection, the poverty rate falls in the repeal states relative to other states for cohorts born after 1970 , as abortion becomes widely available in the repeal states. That is, since the children who are aborted were those who would have lived in the most adverse circumstances, the average living standards of the remaining children improve. Thus, in region B, the poverty rate is (relatively) low among cohorts born in repeal states from 1970 to 1973 . In 1973 abortion becomes legal nationwide. At that point, poverty rates are once again equalized across these two sets of states in region $\mathrm{C}$, as non-repeal states experience a similar improvement in average living circumstances following legalization of abortion. Once abortion is legal nationwide, the difference between the poverty rates in these two states returns to its steady-state (pre-legalization) value.

This stylized depiction suggests two simple tests of the effect of legalization on average living standards. The first is to compare region B to region A: if there is in fact positive selection, as is depicted here, living circumstances should improve for cohorts born after 1970 in the repeal states, relative to the non-repeal states. The second test is to compare region $\mathrm{C}$ to region $\mathrm{B}$ : once again, under the hypothesis of positive selection, relative living circumstances should improve for cohorts born after 1973 in the non-repeal states (or relatively deteriorate in the repeal states). These are the basic tests that we carry out below.

Reality, of course, deviates in at least two significant aspects from this stylized depiction. First, in the absence of abortion reform, there may have been underlying trends in living standards 
across these sets of states; that is, there may have been a falling poverty rate in the repeal states, relative to other states, for reasons other than abortion legalization. This could potentially confound our first test, for example, since there would be a relative decline in adverse living circumstances over time regardless of abortion policy. As we discuss below, this problem is exacerbated in the census data by our use of a single 1980 cross section, which confounds aging and time effects.

We deal with this problem in two ways in our empirical work. First, we introduce distinct quadratic time trends for each state in our analysis, allowing us to distinguish our effects from a (parametric) trend. Second, by finding consistent results from both of the tests described above, we can rule out spurious trends unless they reverse for some reason after period B.

Secolld, the "bounceback" from segment B to segment $C$ may occur less rapidly than does the reduction in adverse circumstances from segment $\mathrm{A}$ to segment B. By being first movers in increasing abortion access, the five repeal states revealed their willingness to make abortion available. The states that were forced into legalization by Roe vs. Wade may have been less positively disposed towards abortion availability, so even de jure legalization may not have implied a large increase in de facto access. ${ }^{9}$ Moreover, the women who wanted abortions most in the nonrepeal states may have travelled to the repeal states to obtain them, so that the shift in use of abortion after Roe v. Wade was muted.

In fact, this view is supported by the evidence on abortion legalization and birth rates in Levine et al. (1996). Their results for the effect of legalization on birth rates are depicted in Figure 2. This figure graphs the relative birth rates of the repeal and non-repeal states over time. Following legalization of abortion in the repeal states in 1970 , birth rates in these states fell

\footnotetext{
${ }^{9} \mathrm{By} 1976$, the non-repeal states contilued to have lower abortion rates and a lower percentage of women living near an abortion provider as compared to repeal states. See Levine et al. (1996), Table 4.
} 
precipitously relative to birth rates in other states. There is then a corresponding fall in birth rates in the non-repeal states after 1973 , so that by 1976 relative birth rates were once again equalized. However, the "bounceback" is slow, only reducing the gap somewhat by 1974-75. Levine et al. present regression results which support the narrative above: relative birth rates fell precipitously in the repeal states during $1971-73$, recovered to some extent by $1974-75$, and fully recovered by $1976-$ 80. Overall, abortion legalization appears to be correlated with roughly a $6 \%$ decline in relative birth rates, which occurred immediately in the repeal states and more gradually in the non-repeal states.

The findings of Levine et al. provide a "first stage" for our analysis. That is, to the extent that we find a change in average living circumstances for a cohort, this can be compared to the change in births for that cohort to infer the living circumstances of the marginal child (i.e. the children that were not born due to abortion legalization). We describe our approach to doing so below. In fact, one finding in Levine et al. is suggestive of positive selection: they find that the effect on the birthrate is largest among teen mothers. This does not prove positive selection, of course, since the set of teen mothers who chose to abort in response to legalization may have been drawn from the highest part of the income distribution (as is suggested by the findings of Cooksley (1990) and Lundberg and Plotnick (1995)). We therefore turn to a more direct analysis using the 1980 census data.

\section{Part II: Data and Regression Framework}

Data

Our primary data for this exercise is the 5\% Public Use sample of the 1980 Census. These data have two important advantages for our purposes. First, they include information on state of 
birth for each child. State of birth, rather than current state of residence, is necessary for correctly determining how abortion laws at the time of birth affected selection into the cohort. Using state of residence in 1980 would potentially bias our findings if there is selective migration; for example, if those children born into poor living circumstances because abortion is not available are more likely to move, using state of residence would understate the impact of making abortion available. Therefore, all of our analyses define cohort according to the child's state and year of birth.

Second, the census samples are the largest available for analysis of living circumstances. This is important because, even with the fairly large change in birth rates documented by Levine et al. (1996), changes in average living circumstances of a birth cohort will only change quite modestly. For example, consider the effects of abortion legalization if there is positive selection. Suppose that the baseline poverty rate in a birth cohort is $15 \%$, and that the marginal births that do not occur because abortion is available would have been $50 \%$ more likely to live in poverty than the average birth in a cohort. This implies a fall in the share of children living in poverty of about half a percentage point from a $6 \%$ drop in the birth rate, a quite small change on average despite this sizeable positive selection effect on the margin. Thus, very large sample sizes are required to identify even sizeable selection effects.

The major cost to using the census for our analysis, as opposed to some source of annual data, is that we cannot separately identify aging effects and time effects within a given cohort; children born later will also be younger in the 1980 census. The importance of this problem is illustrated by considering a simple comparison of the poverty rates of children born in non-repeal states in 1972 and 1976 , using the 1980 census data. If there is a positive selection into abortion, then the average poverty rates of those born in the non-repeal states should decline between these two years. But at the same time, those born in 1972 and 1976 are of different ages in 1980 (8 and 
4 , respectively). Suppose further that mothers of children who are less than 6 do not work, but once children enter school they go to work. Then we would automatically see a countervailing increase in poverty rates over time in the non-repeal states, simply because the children born later are less likely to have a mother in the labor force. Indeed, on average, poverty rates fall with child's age in the 1980 census sample, so that they rise with birth year in this cross section. This increase could mask true positive selection effects. Thus, by confounding aging and time effects, we potentially introduce a spurious trend into our analysis.

Of course, this is not necessarily a problem for our analysis, since we are comparing the relative change in poverty rates (or other outcomes) in the repeal and non-repeal states. But it may introduce problems if there are reasons to believe that child age effects have different impacts in different states. Indeed, visual inspection of the data suggests that there are underlying trends in the state differentials, with a steady relative rise since the mid-1960s in adverse living circumstances in the repeal states. Thus, as described in more detail below, we include state-specific quadratic trends in our regression framework. These controls should capture differences across states, for example, in the work patterns of mothers as their children age. Our estimates of interest are identified by the deviation of average living circumstances around these state-specific trends when abortion is legalized. ${ }^{10}$

Our sample consists of all non-institutionalized children in the 1980 census born between 1965 and 1979 , which is roughly 2.4 million observations. ${ }^{11}$ We focus on three measures of adverse living circumstances: living in poverty; living in a single parent household; and living in a

\footnotetext{
${ }^{10} \mathrm{We}$ also experimented with trends which have a break in 1974 , for the age at which children enter school so that mothers return to work; the results are similar using that approach.

${ }^{11}$ We do include children living in group quarters, such as halfway houses.
} 
household receiving welfare. To construct the first measure, we simply compare total household income to the poverty line for that size household. The second measure is a dummy variable which is equal to one if the child has an unmarried mother or is the child of a male head of household/subfamily with no spouse/partner present, and is zero if there is a second parent. ${ }^{12}$ The final measure is a dummy variable for whether the child's household reports receiving any public assistance income. ${ }^{13}$

While we have 2.4 million observations in the Census, our independent variables of interest vary only at the state and year level. Therefore, we aggregate these census data into state of birth/year of birth cells, and perform all of the analysis at the cell level, weighting the regressions by the cell counts.

A key question for the analysis, of course, is "how adverse" these circumstances are. The outcome of most direct policy relevance is welfare receipt; if changes in abortion availability are associated with changes in welfare receipt, there is a direct implication of abortion policy for the government budget. For the other outcomes, there are a number of studies which suggest that there are negative long run implications on child development, as reviewed by Haveman and Wolfe (1995). Past research has documented a strong positive correlation between parental income when a child is

\footnotetext{
${ }^{12} \mathrm{~A}$ key issue in constructing this measure is assigning children who are not clearly identified as a child of the household head or of a subfamily head. If other relatives of the head were present, we were able to assign some children to those persons; ie. nieces of the head could be assigned if the sister of the head was co-residing and reported having had children. If there was a co-residing partner of the head, children of the head were assigned to that partner as a second parent (if she reports having had children). Finally, if there was a roommate, boarder, or employee in the household who reported having had children, then unrelated children in the household were assigned to that person. Of the children living in single parent households, $10.4 \%$ were living with the father and the remainder with the mother.

${ }^{13}$ This may consist of either AFDC income or other forms of welfare income (ie. state general assistance programs). For the purposes of our policy simulations below, we assume that this is only AFDC income.
} 
young and subsequent high school graduation rates, years of education, and earnings, and a strong negative correlation between parental income and future out-of-wedlock childbearing. Similarly, there is a strong negative correlation between growing up in a single parent family and positive schooling/earnings outcomes, and a positive correlation between growing up in a single parent family and own out of wedlock childbearing. ${ }^{14}$

Of course, these findings are not necessarily relevant for selection through abortion. The effect of being born into a poor or single parent household on average may be quite different than the effect of being born into a poor or single parent household because abortion is restricted. For example, Akerlof, Yellen, and Katz (1996) argue that "shotgun marriages" are likely to be the ones that are sensitive to abortion incentives; but two parent families that are forced to marry may not necessarily provide a higher quality home life than do single parent families.

Ideally, we would extend our analysis to consider the effects of abortion access for the actual later outcomes (ie. schooling completion, fertility decisions, labor force behavior) of these cohorts. We have attempted to do so using the 1990 census, and our results were not fruitful. The confounding of aging and time effects in those data were much more serious than in 1980, perhaps because the ages of the relevant cohorts in 1990 (roughly ages 13-20) are ages of extensive transition in living circumstances, schooling, and work. As a result, parametric trends were insufficient to capture trends in the relative patterns of behavior across states. We return to this issue in our conclusions.

In addition to the census data, we use data on birth rates and birth outcomes, available by state of birth and year of birth from Vital Statistics of the United States. Average birth rates are calculated for all women between the ages of 15 and 44 . For each state-of-birth/year-of-birth cohort

\footnotetext{
${ }^{14}$ See the studies reviewed in Tables $2 \mathrm{a}-6 \mathrm{~b}$ in Haveman and Wolfe (1995).
} 
we focus on two additional measures of adverse living circumstances using these data: the infant mortality rate, or the proportion of children born who die in the first year of life; and the proportion of births that were low birth weight (under 2500 grams). Both measures are standard measures of adverse birth outcomes that have been shown by others (using quite different methods from ours) to be negatively related to abortion access. Furthermore, being born low birth weight has been shown to be correlated with subsequent adverse child outcomes such as cerebral palsy of significant degree, major seizure disorders, blindness, deafness, and learning disorders (McCormick et al., 1992; OTA, 1987; Chaikind and Corman, 1990). While our primary focus is on how abortion affects living circumstances, it is obviously also of interest to assess the health at birth of the marginal child.

\section{Regression Framework}

Our discussion thus far suggests the following regression framework for estimating the effect of abortion legalization on average living circumstances:

$$
\begin{aligned}
\text { OUTCOME }_{\mathrm{it}}= & \beta_{1} \text { REPEAL }_{\mathrm{i}}^{*} \text { D7173 }+\beta_{2} \text { REPEAL }_{\mathrm{i}}^{* D 7475}+\beta_{3} \text { REPEAL }_{\mathrm{i}}^{*} \text { D7679 }+\beta_{4} \delta_{\mathrm{i}} \\
& +\beta_{5} \tau_{\mathrm{t}}+\beta_{6} \delta_{\mathrm{i}}^{*} \text { TREND }+\beta_{7} \delta_{\mathrm{i}}^{*} \text { TRENDSQ }+\epsilon_{\mathrm{it}}
\end{aligned}
$$

where: OUTCOME $\mathrm{it}_{\mathrm{i}}$ is one of the measures of living circumstances described above for the cohort of children born in state $i$ in year $t$; REPEAL $_{i}$ is a dummy for a cohort born in a repeal state; D7073, D7475, and D7680 are dummies for the eras 1971-73, 1974-75, and 1976-80, respectively; $\delta_{\mathrm{i}}$ is a set of state dummies; $\tau_{\mathrm{t}}$ is a set of year dummies; and TREND and TRENDSQ are linear and squared time trends.

Within this regression framework, the impact of abortion legalization in the repeal states (the change from segment $A$ to segment $B$ in Figure 1) is captured by the coefficient $\beta_{1}$; for example, if there is positive selection, we will see a coefficient $\beta_{1}<0$ (since these are adverse measures). The 
impact of abortion legalization in the non-repeal states (segment B vs. C in Figure 1) is captured by $\beta_{3}-\beta_{1}$; again, if there is positive selection, we will see $\beta_{3}>\beta_{1}$. In addition, it is independently of interest to assess whether there is a "full bounceback" $\left(\beta_{3}=0\right)$.

In addition, we therefore pursue two additional tests, which place some more structure on the model but allow us more power in testing for the effects of legalization. First, we impose the restriction that the repeal*76-79 interaction $\left(\beta_{3}\right)$ is zero (which is never rejected in our results below). Imposing this restriction increases the precision with which the repeal*71-73 interaction $\left(\beta_{1}\right)$ is estimated. An even weaker test is simply to ask whether there is any evidence of a shift in the relative time/age pattern of these variables, conditional on including trends; that is, to test for the presence of any change and bounceback, rather than testing individually for each. We do so by testing whether the coefficients on the repeal interactions are jointly zero, as would be true if there were no significant breaks in the relative time/age trend.

\section{The Marginal Child}

Estimates of the impact of abortion legalization on average living circumstances can be combined with estimates of the impact of abortion legalization on birth rates to infer the living circumstances of the marginal child, much the same way that average cost curves can be used to infer marginal cost (e.g. Berndt, 1991). The simplest way of doing this is through direct estimation of the relationship between average living circumstances of a cohort and its birth rate. In particular, suppose that we regress the percentage of a birth cohort with a particular outcome on the log birth rate for that cohort:

$$
\begin{aligned}
\operatorname{OUTCOME}_{\mathrm{it}} \equiv \mathrm{O}_{\mathrm{it}} / \mathrm{B}_{\mathrm{it}}=\alpha_{1} & \ln \left(\mathrm{BIRTHRATE}_{\mathrm{it}}\right)+\alpha_{2} \delta_{\mathrm{i}}+\alpha_{3} \tau_{\mathrm{t}} \\
& +\alpha_{4} \delta_{\mathrm{i}} * \text { TREND }+\alpha_{5} \delta_{\mathrm{i}}^{*} \text { TRENDSQ }+\epsilon_{\mathrm{it}},
\end{aligned}
$$


where $B_{i t}$ is the number of children born in state $i$ and year $t, O_{i t}$ is the number of those children born in state $i$ and year $t$ with a given outcome, and BIRTHRATE $\mathrm{it}_{\mathrm{it}}$ is the birthrate to women of childbearing age in state $\mathrm{i}$ and year $\mathrm{t}$ (i.e. BIRTHRATE $\mathrm{it}_{\mathrm{it}}=\mathrm{B}_{\mathrm{it}} /(\#$ women of childbearing age in state $i$ and year $t)$ ). Taking the derivative of equation (2) with respect to the size of the birth cohort $\left(B_{i t}\right)$, implies that (suppressing subscripts for convenience) $\alpha_{1}=\mathrm{dO} / \mathrm{dB}-\mathrm{O} / \mathrm{B}$. In other words, the coefficient $\alpha_{1}$ from equation (2) is an estimate of the gap between the marginal outcome and the average outcome in the cohort.

Alternatively, if we specify the relationship between average outcomes and the birth rate as:

$$
\begin{aligned}
\ln \left(\text { OUTCOME }_{\mathrm{it}}\right)=\ln \left(\mathrm{O}_{\mathrm{it}} / \mathrm{B}_{\mathrm{it}}\right)=\alpha_{1}{ }^{\prime} & \ln \left(\mathrm{BIRTHRATE}_{\mathrm{it}}\right)+\alpha_{2}{ }^{\prime} \delta_{\mathrm{i}}+\alpha_{3}{ }^{\prime} \tau_{\mathrm{t}} \\
& +\alpha_{4}{ }^{\prime} \delta_{\mathrm{i}}{ }^{*} \text { TREND }+\alpha_{5}{ }^{\prime} \delta_{\mathrm{i}} * \text { TRENDSQ }++\epsilon_{\mathrm{it}},
\end{aligned}
$$

then similar logic implies that $\alpha_{1}{ }^{\prime}=(\mathrm{dO} / \mathrm{dB}-\mathrm{O} / \mathrm{B}) /(\mathrm{O} / \mathrm{B})$. In other words, if we log the dependent variable, the coefficient $\alpha_{1}{ }^{\prime}$ becomes an estimate of the gap between the marginal outcome and the average outcome stated in percentage terms.

One might expect OLS estimates of equation (2) or (2') to misstate the amount of selection associated with abortion legalization, because much of the variation in birth rates is not due to changes in abortion access. Other year-to-year variation in birth rates may induce selection which is either positive or negative, but which is independent of selection through abortion. Regardless of the direction, to the extent that this year-to-year variation embodies relatively small selection effects, OLS estimates will understate the differences between the average child and the marginal child not born due to abortion access.

In order to isolate the selection effects of abortion legalization, we therefore estimate these equations by two stage least squares, using the variation in abortion legalization across states and years to instrument for the birthrate. The first stage equation is: 


$$
\begin{aligned}
\ln \left(\text { BIRTHRATE }_{\mathrm{it}}\right)= & \beta_{1} \text { REPEAL }_{\mathrm{i}}^{*} \text { D7173 }+\beta_{2} \text { REPEAL }_{\mathrm{i}}^{*} \text { D7475 }+\beta_{3} \text { REPEAL }_{\mathrm{i}}^{*} \text { D7679 } \\
& +\beta_{4} \delta_{\mathrm{i}}+\beta_{5} \tau_{\mathrm{t}}+\beta_{6} \delta_{\mathrm{i}}^{*} \text { TREND }+\beta_{7} \delta_{\mathrm{i}}^{*} \text { TRENDSQ }+\epsilon_{\mathrm{it}}
\end{aligned}
$$

Thus, equations (1) and (3) are reduced form equations relating abortion legalization to average child outcomes and to birth rates. Equation (2) or (2'), estimated by two stage least squares, is the structural equation from which we estimate the difference between the average child outcome and the outcome of the marginal child whose birth is affected by abortion legalization.

\section{Part III: Results}

\section{Impact of Abortion Legalization on Average Child Outcomes}

Regression results for the reduced form equations (1) and (3) are in Table 1. Each column of the table has test results and coefficients of interest from a separate regression. For each regression we report the coefficients for the repeal interactions $\left(\beta_{1}\right.$ through $\beta_{3}$ in equation (1)), the p-value from a test of $\beta_{1}=\beta_{3}$ (i.e. comparing segment B vs. segment $C$ in figure 1 ), and the p-value from a test of joint significance of the repeal interactions (the weak test described above).

The first two columns report estimates of the first stage equation (3), in which the dependent variable is the $\log$ birth rate. These columns replicate the results of Levine et al (1996), and the coefficients suggest that abortion legalization reduced the birth rate by about 6 percent. In particular, birth rates fell by about $6 \%$ in repeal states relative to non-repeal states in 1971-73 $\left(\beta_{1}=-0.059\right)$, but then birth rates in non-repeal states fell relative to repeal states following legalization in all states in $1973\left(\beta_{1}-\beta_{3}=-0.072\right)$. Thus, we estimate significant effects of abortion on birth rates of similar

magnitude in both the repeal and non-repeal states. As a result, we cannot reject the hypothesis that there was a full bounceback in relative birth rates $\left(\beta_{3}=0\right)$. The second column reports the results when $\beta_{3}$ is constrained to be zero, and the results are quite similar. In both specifications, the repeal 
interactions are highly jointly significant.

The remaining columns of Table 1 estimate equation (1) for alternative outcome measures. In each case, we multiply the coefficients of interest by 100 , so that they can be interpreted as percentage point effects.

For the percentage of a cohort living in single-parent households, the pattern of coefficients is very supportive of positive selection; that is, the legalization of abortion lowers the share of children living in single-parent households. Legalization in the repeal states over the 1971-73 period is associated with a reduction in the percentage of children living in single parent families of 0.97 percentage points (supporting positive selection for segment B vs. segment A). This effect was reduced to some extent over the $1974-1975$ period, and was gone completely by 1976-1979. More importantly, the coefficients on the 1971-73 and 1976-79 interactions are significantly different from each other (confirming positive selection in the non-repeal states, segment $\mathrm{C}$ vs. segment $\mathrm{B}$ ). Whether or not we impose the full bounceback $\left(B_{3}=0\right)$, the repeal interactions are very jointly significant.

For the percentage of the cohort in poverty, the directions of the coefficients support positive selection, but the estimates are imprecise. There is a negative coefficient on the 1971-73 interaction but it is insignificant, and there is an insignificant positive coefficient on the 76-79 interaction, although it is fairly large. Despite the imprecision of these estimates, however, we can reject that the 1971-73 and 1976-79 interactions are equal at the 5.3\% level, which supports positive selection. If we impose $B_{3}=0$, then the 71-73 interaction becomes negative and significant, suggesting that abortion legalization reduced the percentage of the cohort living in poverty by 0.46 percentage points. And, once again, the repeal interactions are jointly significant.

For welfare receipt, the coefficient are also supportive of positive selection, with a negative 
and significant coefficient on the 1971-73 interaction, and a zero coefficient on the 1976-79 interaction. The results indicate that abortion legalization lowered welfare receipt rates by 0.41 percentage points on average. However, the relative imprecision here means that we are unable to reject the equality of the 1971-73 and 1976-79 interactions. Unexpectedly, the 1974-75 interaction is actually larger than the 1971-73 interaction although these coefficients are not very precisely estimated. And we can again reject the joint insignificance of the repeal interactions.

The final columns look at the impact of abortion legalization on infant mortality and on the percentage of the birth cohort that was low birth weight. As with the measures of living circumstances in 1980 from the census data, these birth outcome measures suggest positive selection: a negative coefficient on the 1971-73 interaction (but only significant for infant mortality) and a zero (or at least insignificant) coefficient on the 1976-79 interaction. While the results for mortality are more statistically significant, the magnitudes are very similar for the two variables: in the more restrictive model of columns (10) and (12), we find that the rate of low birthweight falls by 0.07 percentage points and the rate of infant mortality falls by 0.05 percentage points. This supports the notion that changes in infant mortality are arising through selection on fetal health, as reflected in birthweight. ${ }^{15}$

Overall, the pattern of estimates is very suggestive of positive selection. The 1971-73 interaction $\left(\beta_{1}\right)$ is negative in every case. It is statistically significant for three of our five outcomes; and when we impose the restriction that the repeal*76-79 interaction is zero (which is not rejected in any of our models), it becomes significant in every case (although only marginally for low birth

\footnotetext{
${ }^{15}$ This finding is almost identical to the finding for whites of Grossman and Jacobowitz (1981), who estimate a 0.059 percentage point decline in neonatal mortality for whites in abortion reform states after 1970 . It is substantially smaller than their estimate of a 0.177 percentage point decline for blacks, however.
} 
weight). Similarly, in each regression we find that this difference is reversed after legalization of abortion in the non-repeal states in 1973 (i.e. $\beta_{3}>\beta_{1}$ ), although this difference is only significant for living in a single-parent or poverty household. And, for all outcomes, the repeal interactions are found to be jointly significant at least at the $10 \%$ level. Thus, abortion legalization appears to be associated with an improvement in the average living circumstances and birth outcomes among a birth cohort.

\section{Single Parent Households vs. Changes in Income Distribution}

Our results thus far indicate that abortion legalization leads to significant reductions in both the share of children living in single parent families and the share living in poverty. Single parent families are much poorer than other families, however; in our sample, the poverty rate among those children in single parent families is $45 \%$, as compared to only $13 \%$ in other, primarily two-parent, families. ${ }^{16}$ As a result, our finding that fewer children are living in poor households may arise mechanically from the reduction in the odds of residing in a single parent household, rather than from increases in the average income of families, conditional on family structure. The previous literature, in fact, suggests that we should find a reduction in the average income of children living in single parent families, since micro-data studies of teen unmarried childbearing find negative selection on abortion decisions (Cooksley, 1990; Lundberg and Plotnick, 1995).

We can examine this question by considering specifically the effect of legalization on family structure-conditional poverty rates. More specifically, we compute state/year specific poverty rates

\footnotetext{
${ }^{16}$ In fact, $4 \%$ of the children in our sample are coded as living in neither a two parent or one parent household. These are children for whom we were able to identify a mother who was not the household head or spouse, but we were not able to confirm whether or not there was a coresiding partner. For example, in some cases we identified the mother and also another coresiding male in the household, but we could not definitively state whether the male was the partner of the woman.
} 
among the single parent and two parent family samples, and use these as dependent variables. If our result is driven by the compositional shift in family structure, then we should find no effect of legalization on poverty rates within these samples once they are stratified by family structure.

In fact, as Table 2 shows, this is exactly what we find. There is no effect of legalization on either the share of single parent families in poverty or the share of other families in poverty; we fail every single test described above (although standard errors are considerably larger as well, particularly for the single parent sample). Thus, it appears that our findings for changes in poverty when abortion becomes available is driven solely by changes in the distribution of family structure. ${ }^{17}$

\section{Outcomes for the Marginal Child}

While our findings for these average measures of disadvantage in a cohort are fairly consistent in their signs and significance, it is of interest to interpret these magnitudes in terms of the size of the selection effect. That is, we can ask: what are the characteristics of the marginal children who were not born due to abortion legalization? Estimates of the difference between the marginal and the average birth outcome are presented in Table 3.

Each column in Table 3 reports OLS and two stage least squares (TSLS) estimates of the coefficient on the log birth rate from a regression of our average outcome measures on the log birth rate (equation 2 or 2'). The TSLS estimates instrument for the birth rate with the repeal interactions. Thus, column 1 of Table 1 reports the first stage equation for the TSLS estimates. ${ }^{18}$ As discussed

\footnotetext{
${ }^{17}$ Note that our finding of no selection conditional are inconsistent with the findings of Cooksley (1990) and Lundberg and Plotnick (1995); this suggests that these earlier findings may be due to positive reporting bias in the NLSY data.

${ }^{18}$ The first stage $\mathrm{F}$ statistics for this table are very high; in every case the $\mathrm{F}$ is over 60 .
} 
earlier, these coefficients estimate the gap in child outcomes between the marginal and the average child. For specifications in which the dependent variable is logged, the coefficient gives this gap as a percentage of the average outcome. In addition to the OLS and TSLS estimates, we report the pvalue of a test that the OLS and TSLS estimates are equivalent, and the p-value from a test of the over-identifying restrictions in the TSLS models.

The first panel considers the likelihood that the marginal child would have lived in a single parent household in 1980. The OLS estimate in the first column indicates that the marginal child would have been 6 percentage points more likely to live in such a household, as compared to the average child in their cohort. Alternatively, column 2 estimates that the marginal birth was approximately $34 \%$ more likely to live in a single parent household. As discussed earlier, however, one would expect OLS estimates to underestimate the selection effects of legalization because much of the variation in birth rates is not the result of changes in abortion access.

Indeed, when we instrument in the second row, our estimates rise appreciably. The TSLS estimates indicate that the marginal birth being affected by abortion legalization would have been 14.4 percentage points more likely to have been living in a single-parent household in 1980 , as compared to the average child in their cohort. Column (2) shows that the marginal birth was nearly $70 \%$ more likely to live in a single parent household. Both estimates are fairly precisely estimated. Finally, the test of the over-identifying restrictions has a $\mathrm{p}$-value of 0.275 , providing no evidence of mis-specification in the TSLS model.

The remaining columns provide similar estimates for other outcome measures. The TSLS estimates imply that, compared to the average outcome in their birth cohort, the marginal birth would have had higher poverty rates in 1980 ( 7.6 percentage points or $38 \%$ higher), and been more likely to have lived in a family receiving welfare in 1980 (5.73 percentage points or $48 \%$ more). 
Similarly, the marginal birth would have had higher infant mortality rates $(0.69$ percentage points or $34 \%$ higher) and higher incidence of low birth weight (1.13 percentage points or $14 \%)$. With the exception of low birth weight, these estimates are statistically significant at or near the $5 \%$ level. Furthermore, all specifications pass the test of over-identifying restrictions.

All of the TSLS estimates are larger than the OLS estimates. This would be expected if there was stronger selection arising from changes in abortion access, than arising from other factors that influence the birthrate. In fact, the gap between OLS and TSLS estimates may understate the difference in selection due to abortion versus other factors, since a large share of the year-to-year variation in birth rates that identifies our OLS estimate comes from changes in abortion access. We address this in the final row of the table, by reestimating our OLS regression excluding the years 1971-1975. By considering only those years during which there was no difference across states in the legality of abortion, we provide an estimate of the effect of year-to-year variation in birth rates for reasons other than abortion legality. Indeed, our estimates here are smaller. For the census variables, the estimates are only one-third to two-thirds as large as the full-sample OLS estimates, and only the results for residing in a single parent household is (marginally) significant. For the birth outcomes variables, the coefficients become negative.

This comparison of OLS and TSLS estimates helps us to address an alternative hypothesis for our findings: crowding. If there are fixed costs to adjusting public resources, then changes in cohort size may change outcomes through loosening or tightening congestion effects. This is most obvious for the case of education: if teachers unions or other rigidities make it difficult to adjust the number of teachers as cohort size falls, then there will be fewer students per teacher and potentially 
improved student outcomes as a result. ${ }^{19}$ This type of congestion effect could lead to improved outcomes on average when legalization reduced cohort sizes, regardless of selection effects.

In practice, there are two reasons to believe that cohort size changes are not driving our results. First, it is difficult to construct congestion-type stories for the outcomes that we examine, household characteristics or birth outcomes; for welfare receipt, such stories would presumably bias against our findings, if states maintain their welfare budgets in the face of a declining cohort. Second, unless there are non-linear congestion effects, then the OLS estimates, and in particular the estimates for the years excluding 1971-75, provide a direct assessment of the impact of congestion. In fact, as we have shown, there is little effect of changes in cohort size on our outcomes of interest over this period. In every case, the OLS estimates in the final row of the table are much smaller (or even of a different sign) then their 2SLS counterparts.

\section{Implications}

The implication from these findings is that the marginal children who were not born due to abortion legalization would have lived in much worse circumstances than the average child in their cohort. This indicates sizeable positive selection among those pregnancies that were carried to term following legalization of abortion. In other words, this evidence strongly suggests that abortion is used by women to avoid bearing children who would grow up in adverse circumstances.

As noted above, this is a purely positive exercise, and we do not have much insight into the long run implications of this change in average living standards. One clear implication of our

\footnotetext{
${ }^{19}$ Indeed, changes in cohort size have been used in two recent papers to identify the effect of class size on student outcomes: Hoxby (1996) finds that cohort-size induced variation in class size in Connecticut had no effect on student outcomes, while Angrist and Lavy (1997) find that cohortsize induced variations in class size in Israel were inversely correlated with student performance.
} 
findings, however, is that there was a substantial effect of abortion legalization on the budgets of federal and state governments, through reduced welfare receipt. We can compute the budgetary savings to the government through the reduced welfare receipt of the average child after abortion legalization. In doing so, we abstract from welfare savings due to the overall drop in cohort size; we are only estimating the differential savings arising from the change in cohort mix through positive selection.

Our calculation proceeds as follows. First, we compute the drop in the number of children born into welfare households the year after the legalization due to selection, as the product of the size of the birth cohort, the percentage reduction in the birth rate $(0.063$, from column (2) of Table 1$)$, and the difference between the welfare receipt rate of the average and marginal birth $(0.057$, from column (5) of Table 3). We treat the year after legalization as 1971 in the repeal states, and 1976 in the non-repeal states. We estimate that in this year, the lower average welfare receipt rate in this cohort, due to positive selection only, reduced the welfare caseload by 13,868 families. In 1995 dollars, the average welfare payment per family of two (mother and child) in the year after legalization was $\$ 6477 .{ }^{20}$ This implies that the government saved $\$ 90$ million dollars per cohort per year through abortion legalization in these states.

While this is a relatively small figure, the reduction in welfare spending is a steady state reduction for the entire future. That is, in the year after legalization, there would be an additional savings for the next birth cohort, as well as continued savings for the initial post-legalization birth cohort. Assuming that the lower welfare participation rates are maintained until the cohort reaches age 18 , we estimate that the cumulative government savings through the year 1994 from legalization

\footnotetext{
${ }^{20}$ We use benefits for a family of two because the mechanism through which abortion legalization reduced welfare receipt appears to be through reducing the initial formation of single female headed families.
} 
was roughly $\$ 14$ billion in 1995 dollars. By 1993 all cohorts under age 18 were born under legalized abortion, and we estimate steady state savings of $\$ 1.6$ billion per year from positive selection.

\section{Part IV: Conclusions}

The most important change in government fertility policy over the past 30 years was the legalization of abortion under the Roe v. Wade decision. As has been shown elsewhere, this change had a dramatic effect on the size of birth cohorts. As we demonstrate in this paper, the change also had a significant effect on the living circumstances of the cohorts that were born after legalization. Subsequent cohorts were less likely to be in single parent households, and as a result less likely to live in poverty, and less likely to receive welfare. In addition, these cohorts experienced lower infant mortality. In particular, we find that for the marginal child not born due to increased abortion access, the odds of living in a single parent family would have been roughly $70 \%$ higher, the odds of living in poverty nearly $40 \%$ higher, the odds of welfare receipt $50 \%$ higher, and the odds of dying as an infant $35 \%$ higher. From these results, we estimate that the legalization of abortion saved the government over \$14 billion in welfare payments through 1994.

Perhaps more importantly, these findings also potentially have implications for the lifelong prospects of the average child born after legalization. The children not born due to abortion availability would have grown up in adverse living circumstances which have been shown in other work to have very detrimental effects on later prospects. Of course, as we note above, this conclusion is complicated by the fact that we cannot necessarily apply the effects on the average child of living in poverty (for example) to the effects on the marginal child who would live in poverty if their pregnancy was not terminated. However, as these cohorts age, researchers will be able to 
directly observe outcomes such as educational attainment, income, and family structure, for example using the year 2000 U.S. Census, to assess whether such outcomes improved for the average person born after legalized abortion. This is an important question that should be the focus of future analysis. 


\section{References}

Akerlof, George, Janet Yellen and Michael Katz, "An Analysis of Out-of-Wedlock Childbearing in the United States," Quarterly Journal of Economics, 111(2), May 1996, 277-318.

Angrist, Joshua D. and Victor Lavy, "Using Maimonides' Rule to Estimate the Effect of Class Size on Scholastic Achievement," National Bureau of Economic Research Working Paper \#5888, January 1997.

Becker, Gary S, A Treatise on the Family. Cambridge, MA: Harvard University Press, 1981.

Berndt, Ernst, The Practice of Econometrics: Classic and Contemporary, Reading, Mass: AddisonWesley, 1991.

Blank, Rebecca, Christine George, and Rebecca London, "State Abortion Rates: The Impact of Policies, Providers, Politics, Demographics, and Economic Environment," Journal of Health Economics, 15(5), October 1996, 513-553.

Chaikind, Stephen and Hope Corman, "The Special Education Costs of Low Birthweight," National Bureau of Economic Research Working Paper \#3461, October 1990.

Cooksley, Elizabeth C. "Factors in the Resolution of Adolescent Premarital Pregnancies," Demography, 27(2), May 1990, 207-218.

Corman, Hope and Michael Grossman, "Determinants of Neonatal Mortality Rates in the U.S.: A Reduced Form Model," Journal of Health Economics, 4, 1985, 213-236.

Currie, Janet, Lucia Nixon, and Nancy Cole, "Restrictions on Medicaid Funding of Abortion: Effects on Pregnancy Resolutions and Birth Weight," Journal of Human Resources, 31(1), Winter 1996, 159-188.

Garrow, David J., Liberty and Sexuality: The Right to Privacy and the Making of Roe v. Wade, New York: Macmillan Publishing Company, 1994.

Grossman, Michael and Steven Jacobowitz, "Variations in Infant Mortality Rates Among Counties of the United States: The Roles of Public Policies and Programs," Demography, 18(4), 1981, 695713.

Grossman, Michael and Theodore Joyce, "Unobservables, Pregnancy Resolutions, and Birth Weight Production Functions in New York City," Journal of Political Economy, 98(5), 1990, 983-1007.

Haveman, Robert and Barbara Wolfe, "The Determinants of Children's Attainments: A Review of Methods and Findings," Journal of Economic Literature, 33(4), December 1995, 1829-1878. 
Hoxby, Caroline, "The Effects of Class Size and Composition on Student Achievement: New Evidence from Natural Population Variation," National Bureau of Economic Research Working Paper, 1997.

Jones, E.F. and J.D. Forrest, "Underreporting of Abortion in Surveys of U.S. Women: 1976 to 1988," Demography, 29, 1992, 113-126.

Joyce, Theodore, "The Impact of Induced Abortion on Black and White Birth Outcomes in the United States," Demography, 24, 1987, 229-44.

Joyce, Theodore, "The Social and Economic Correlates of Pregnancy Resolution Among Adolescents in New York City, by Race and Ethnicity: A Multivariate Analysis," American Journal of Public Health, 78, 1990, 626-631.

Kane, Thomas and Douglas Staiger, "Teen Motherhood and Abortion Access," Quarterly Journal of Economics, 111(2), May 1996, 467-506.

Levine, Phillip B., Douglas Staiger, Thomas J. Kane, and David J. Zimmerman, "Roe v. Wade and American Fertility," National Bureau of Economic Research working paper \#5615, June 1996.

Levine, Phillip B., Amy B. Trainor, and David J. Zimmerman, "The Effects of Medicaid Abortion Funding Restrictions on Abortions, Pregnancies, and Births," Journal of Health Economics, 15, 1996, 555-578.

Lundberg, Shelly and Robert D. Plotnick, "Adolescent Premarital Childbearing: Do Economic Incentives Matter," Journal of Labor Economics, 13(2), April 1995, 177-200.

McCormick, Barbara, et al., "The Health and Developmental Status of Very-Low-Birthweight Children at School Age," Journal of the American Medical Association, 267, 1992.

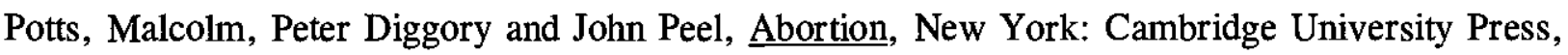
1977.

United States Bureau of Census, Vital Statistics of the United States: Natality, Washington DC: various years.

United States Office of Technology Assessment, Neonatal Intensive Care for Low Birthweight Infants: Costs and Effectiveness, OTA-HCS-38, Washington, D.C.: GPO, 1987.

Ventura, Stephanie, Selma Tavvel, William Mosher, Jacqueline Wilson and Stanley Henshaw, "Trends in Pregnancies and Pregnancy Rates: Estimates for the United States, 1980-92," Monthly Vital Statistics Report, 43(11), Supplement, May 25, 1995. 


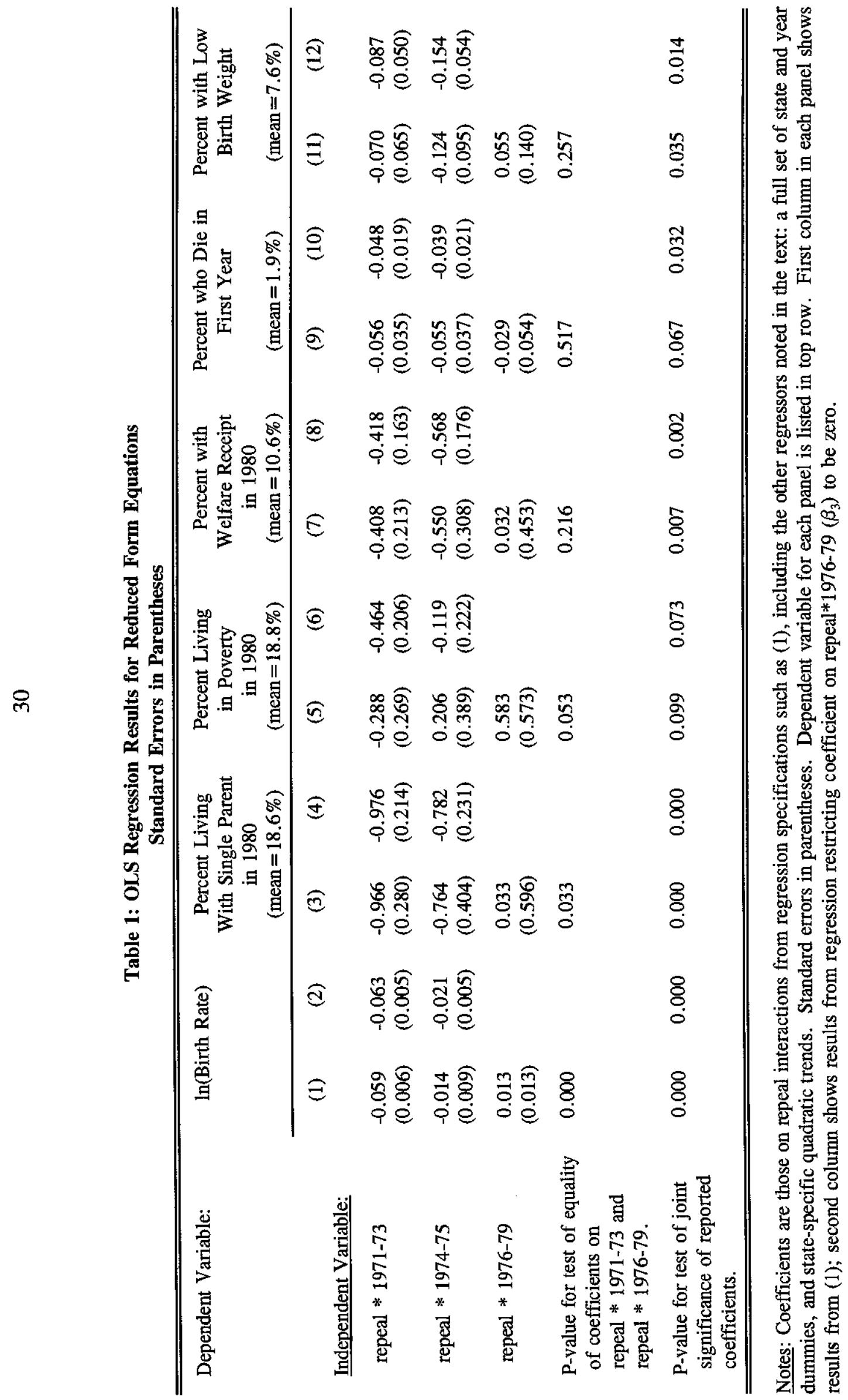


Table 2: OLS Regression Results for Reduced Form Equations Conditioning on Whether Child is in Single-parent Household Standard Errors in Parentheses

\begin{tabular}{|c|c|c|c|c|}
\hline \multirow{3}{*}{$\begin{array}{l}\text { Dependent Variable: } \\
\text { Independent Variable: }\end{array}$} & \multicolumn{2}{|c|}{$\begin{array}{l}\text { Share of Single } \\
\text { Parent in Poverty } \\
(\text { mean }=45.9 \%)\end{array}$} & \multicolumn{2}{|c|}{$\begin{array}{l}\text { Share of non Single } \\
\text { Parent in Poverty } \\
\text { (mean }=12.6 \%)\end{array}$} \\
\hline & (1) & (2) & (3) & (4) \\
\hline & & & & \\
\hline repeal $* 1971-73$ & $\begin{array}{l}-0.015 \\
(0.770)\end{array}$ & $\begin{array}{l}-0.106 \\
(0.591)\end{array}$ & $\begin{array}{c}0.012 \\
(0.253)\end{array}$ & $\begin{array}{l}-0.138 \\
(0.193)\end{array}$ \\
\hline repeal $* 1974-75$ & $\begin{array}{l}-0.140 \\
(1.126)\end{array}$ & $\begin{array}{l}-0.312 \\
(0.642)\end{array}$ & $\begin{array}{c}0.571 \\
(0.364)\end{array}$ & $\begin{array}{c}0.294 \\
(0.208)\end{array}$ \\
\hline repeal $* 1976-79$ & $\begin{array}{c}0.309 \\
(1.669)\end{array}$ & & $\begin{array}{c}0.495 \\
(0.535)\end{array}$ & \\
\hline $\begin{array}{l}\text { P-value for test of joint } \\
\text { significance of reported } \\
\text { coefficients. }\end{array}$ & 0.966 & 0.889 & 0.179 & 0.132 \\
\hline $\begin{array}{l}\text { P-value for test of equality } \\
\text { of coefficients on } \\
\text { repeal } * 1971-73 \text { and } \\
\text { repeal } * 1976-79 .\end{array}$ & 0.806 & & 0.250 & \\
\hline
\end{tabular}

Notes: Coefficients are those on repeal interactions from regression specifications such as (1), including the other regressors noted in the text: a full set of state and year dummies, and state-specific quadratic trends. Standard errors in parentheses. Dependent variable for each panel is listed in top row. First column in each panel shows results from (1); second column shows results from regression restricting coefficient on repeal*1976-79 $\left(\beta_{3}\right)$ to be zero. 


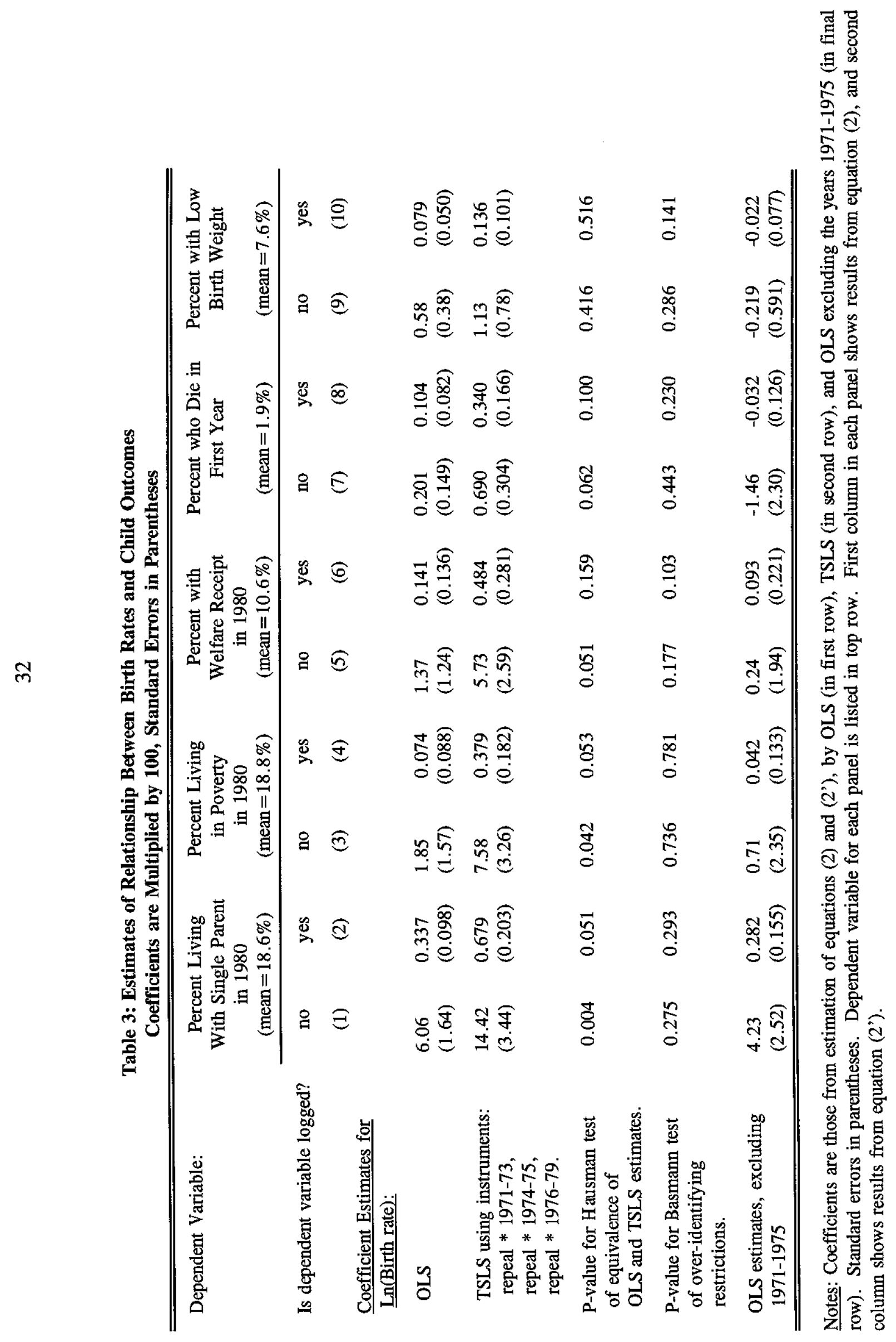




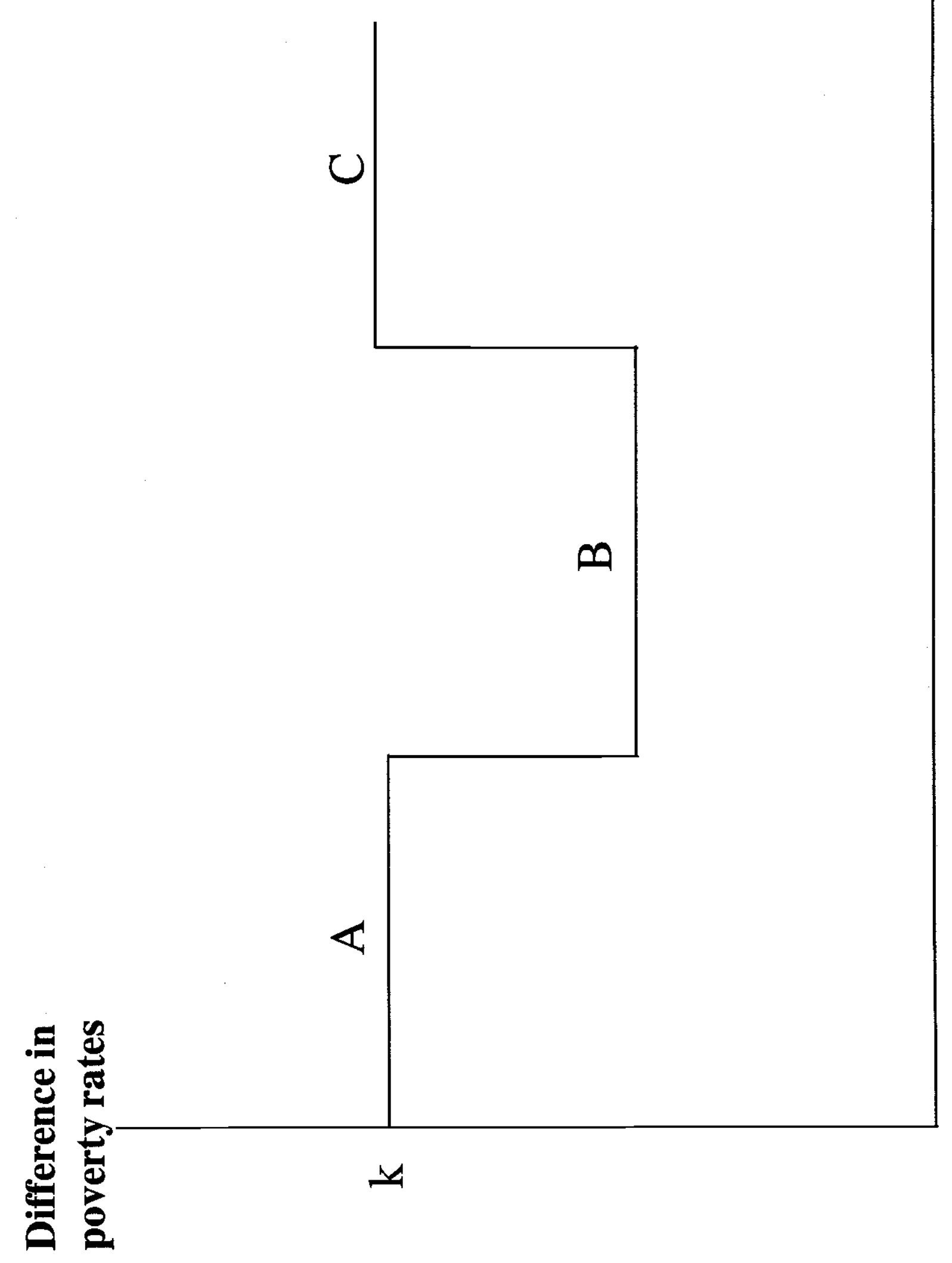

峁

刃্

$\pm$

응

尊

표

엄

.

릉

흥

웡

3

通

i

(1)

8

.

导 


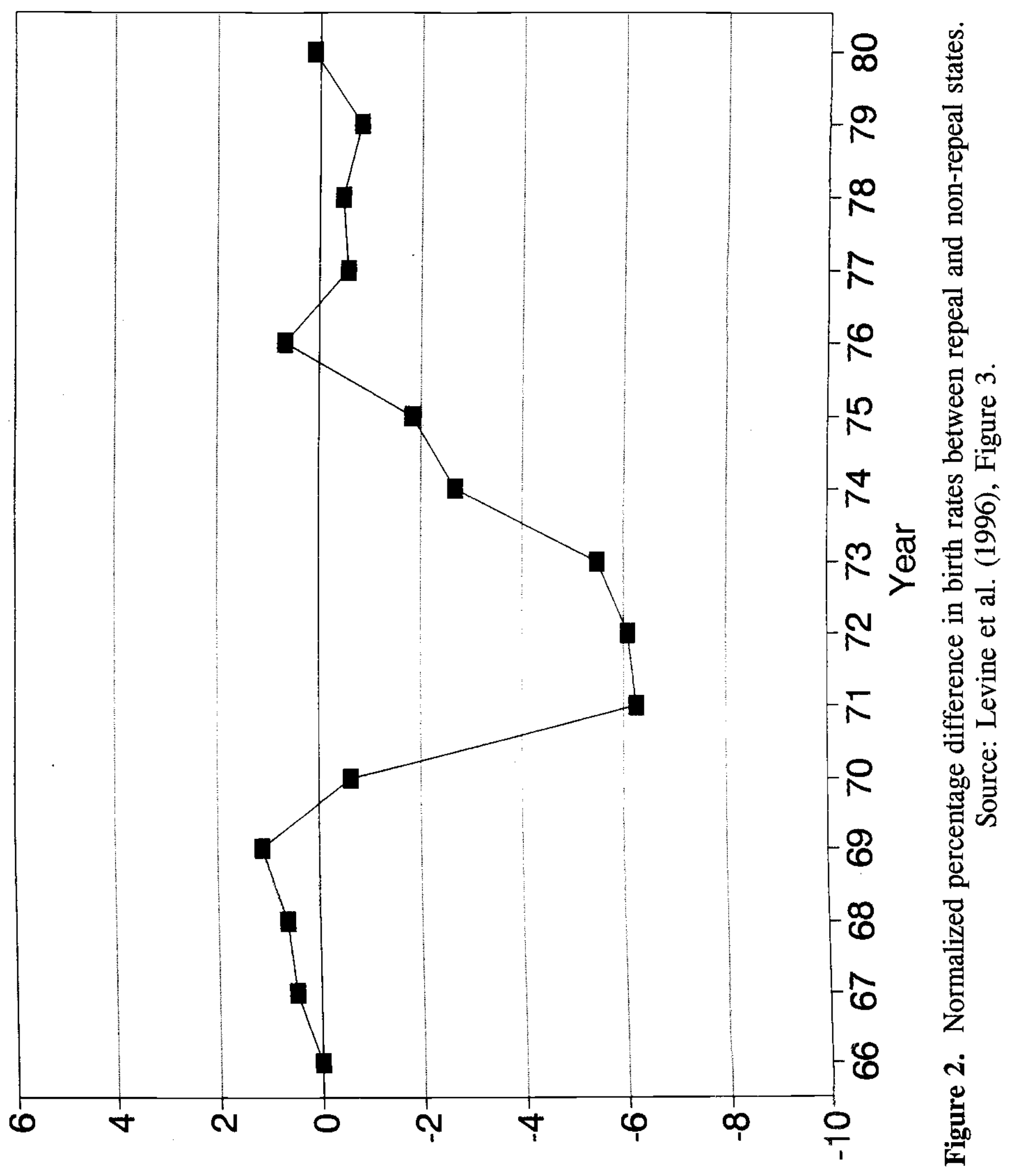

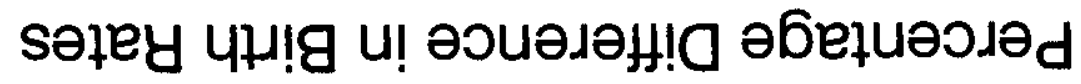

